\title{
Control of high-Z PFC erosion by local gas injection in DIII-D*
}

\author{
D.L. Rudakov ${ }^{1}$, P.C. Stangeby ${ }^{2}$, C.P.C. Wong ${ }^{3}$, A.G. McLean ${ }^{4}$, W.R. Wampler ${ }^{5}$,
} J.G. Watkins ${ }^{6}$, J.A. Boedo ${ }^{1}$, A. Briesemeister ${ }^{7}$, D.A. Buchenauer ${ }^{6}$, C.P. Chrobak $^{3}$, J.D. Elder ${ }^{2}$, M.E. Fenstermacher ${ }^{4}$, H.Y. Guo ${ }^{3}$, C.J. Lasnier ${ }^{4}$, A.W. Leonard ${ }^{3}$, R. Maingi ${ }^{8}$, R.A. Moyer ${ }^{1}$

${ }^{1}$ University of California San Diego, 9500 Gilman Drive, La Jolla, CA, 92093-0417, USA

${ }^{2}$ University of Toronto Institute for Aerospace Studies, Toronto, M3H 5T6, Canada

${ }^{3}$ General Atomics, P. O. Box 85608, San Diego, CA, 92186-5608, USA

${ }^{4}$ Lawrence Livermore National Laboratory, 7000 East Avenue, Livermore, CA, 94550, USA

${ }^{5}$ Sandia National Laboratory, P.O. Box 5800, Albuquerque, NM, 87185, USA

${ }^{6}$ Sandia National Laboratory, P.O. Box 969, Livermore, CA 94551-0969, USA

${ }^{7}$ Oak Ridge National Laboratory, Oak Ridge, Tennessee 37830

${ }^{8}$ Princeton Plasma Physics Laboratory, PO Box 451, Princeton, NJ, 08543 USA

\begin{abstract}
Reduced erosion of a high-Z PFC divertor surface was observed in DIII-D with local injection of methane and deuterium gases. Molybdenum-coated silicon samples were exposed in the lower divertor of DIII-D using DiMES under plasma conditions previously shown to cause significant net erosion of Mo. Three exposures with ${ }^{13} \mathrm{CH}_{4}$ and one exposure with $\mathrm{D}_{2}$ gas injection about $12 \mathrm{~cm}$ upstream of the samples located within 1-2 $\mathrm{cm}$ of the attached strike point were performed. Reduction of Mo erosion was evidenced in-situ by the suppression of MoI line radiation at $386.4 \mathrm{~nm}$ once the gas injection started. Post-mortem ion beam analysis demonstrated that the net erosion of molybdenum near the center of the samples exposed with
\end{abstract}


${ }^{13} \mathrm{CH}_{4}$ injection was below the measurement resolution of $0.5 \mathrm{~nm}$, corresponding to a rate of $\leq 0.04 \mathrm{~nm} / \mathrm{s}$. Compared to the previously measured erosion rates, this constitutes a reduction by a factor of $>10$.

Abstract length (150 words): 149 currently

PACS: $52.40 . \mathrm{Hf}$, 52.55.Fa, 52.55.Rk

PSI-21 Keywords: DIII-D, DIMES, Erosion \& Deposition

*Corresponding and presenting author address: University of California-San Diego, 9500 Gilman Drive, Mail code 0417, La Jolla, California 92093-0417

*Corresponding and presenting author e-mail: rudakov@fusion.gat.com 


\section{Introduction}

High-Z materials such as tungsten will be used for plasma facing components (PFCs) in the divertor of ITER [1] and very likely in devices beyond ITER. PFC erosion will produce high- $\mathrm{Z}$ impurities that may lead to unacceptably high radiation losses if they enter the plasma core. It is envisaged that erosion of the main divertor plates will be controlled by detachment $[2,3]$ induced by injection of radiating gas. However, this may leave some critical PFCs such as divertor baffles, startup/protection limiters, etc., vulnerable to excessive erosion and surface damage including melting, particularly during transients such as Edge Localized Modes (ELMs) and disruptions. A sacrificial low-Z coating deposited on a high-Z PFC surface can protect the surface from erosion and damage. However, a thin coating will quickly erode, so it has to be renewable in-situ. Injection of a gas containing low-Z impurities such as $\mathrm{B}, \mathrm{C}, \mathrm{Si}$, or Li through capillaries at a PFC surface can lead to the local deposition of a low-Z coating on the surface (see Section 2). Pioneering work in TEXTOR [4] demonstrated the effectiveness of in-situ coatings produced by the local injection of silane gas $\left(\mathrm{SiH}_{4}\right)$ for controlling erosion of the leading edge of a graphite limiter. In more recent TEXTOR experiments, local injection of various impurity gases $\left({ }^{13} \mathrm{CH}_{4},{ }^{13} \mathrm{C}_{2} \mathrm{H}_{4}, \mathrm{WF}_{6}\right)$ was performed through test limiters exposed to the edge plasma, and impurity deposition on the limiter surface was studied experimentally and modelled by ERO code (see [5] for a review). However, focus of these experiments was on the deposition process itself rather than protection of the underlying PFC surface. In the experiments reported here, we demonstrated suppression of molybdenum (Mo) surface erosion by using methane gas injection upstream of Mo-coated samples in the DIII-D divertor.

While creating a protective low-Z coating in-situ is an attractive concept, it has certain disadvantages: eroded low-Z impurities would re-deposit elsewhere, potentially leading to tritium retention and accumulation of dust and debris from exfoliating re-deposited layers. In 
case of carbon, this problem may potentially be alleviated by thermal oxidation [6] that is capable of removing both tritium and carbon (thus reducing carbon dust and re-deposited hydro-carbon layers). However, this solution is unlikely to be acceptable for ITER, primarily because of the problems associated with handling highly radioactive and corrosive tritiated water. Therefore, we also tested the reduction of Mo erosion by the local injection of nondepositing $\mathrm{D}_{2}$ gas. This technique, while probably less effective for PFC protection from transients, may possibly be used for alleviating erosion of PFCs where critical heat loads may exist for relatively short and given periods of time, e.g. ITER startup limiters. Localized injection of $\mathrm{D}_{2}$ gas near Ion Cyclotron Range of Frequency (ICRF) antennas in ASDEX Upgrade has been shown to reduce the local sputtering of $\mathrm{W}$ from the antenna limiters [7].

\section{Background: balance between erosion and deposition}

It can be shown from first-principle considerations that local injection of a gas containing low-Z impurity can shift the balance between erosion and deposition of the impurity from net erosion to net deposition. We will use carbon in deuterium plasma as an example. Let the D ion flux density onto the solid surface be $\Gamma_{\mathrm{D}}$ and the $\mathrm{C}$ ion flux density onto the solid surface be $\Gamma_{\mathrm{C}}$. Let the sputtering yield for $\mathrm{D}$ on $\mathrm{C}$ be $\mathrm{Y}_{\mathrm{DC}}$ and for self-sputtering be $\mathrm{Y}_{\mathrm{CC}}$. With a Ccontaining gas injection, $\mathrm{f}_{\mathrm{C}} \quad \Gamma_{\mathrm{C}} / \Gamma_{\mathrm{D}}$ is externally adjustable. Neglecting backscattering, the gross rate at which $\mathrm{C}$ particles deposit on the surface is $\mathrm{f}_{\mathrm{C}} \Gamma_{\mathrm{D}}$ and the rate at which they are removed by sputtering is $\mathrm{Y}_{\mathrm{DC}} \Gamma_{\mathrm{D}}+\mathrm{Y}_{\mathrm{CC}} \mathrm{f}_{\mathrm{C}} \Gamma_{\mathrm{D}}$. Thus for steady state, where the layer thickness remains constant, one has:

$$
\begin{aligned}
& \mathrm{f}_{\mathrm{C}} \Gamma_{\mathrm{D}}=\mathrm{Y}_{\mathrm{DC}} \Gamma_{\mathrm{D}}+\mathrm{Y}_{\mathrm{CC}} \mathrm{f}_{\mathrm{C}} \Gamma_{\mathrm{D}} \\
& \mathrm{f}_{\mathrm{C}}=\mathrm{Y}_{\mathrm{DC}} /\left(1-\mathrm{Y}_{\mathrm{CC}}\right)
\end{aligned}
$$

Note that $f_{C}$ is a function of $T_{e}$ since $Y_{D C}$ and $Y_{C C}$ are, thus eqn. (2) defines $T_{e, t h}\left(f_{C}\right)$, the temperature at which the thickness of the carbon layer neither increases nor decreases. 
Figure 1 shows the calculated dependence of $T_{e, t h}\left(f_{C}\right)$ (details of the calculation will be published in a dedicated paper). Physical sputtering yields from [8] and chemical sputtering yields from [9] for $300 \mathrm{~K}, 500 \mathrm{~K}, 800 \mathrm{~K}$ and $1000 \mathrm{~K}$ were used. The curves in the figure correspond to balance between erosion and deposition. The regions to the left of the curves correspond to net erosion and the regions to the right correspond to net deposition. Thus, for a given surface temperature, the transition from net erosion to net deposition of carbon can be achieved by either increasing $\mathrm{f}_{\mathrm{C}}$ or decreasing $\mathrm{T}_{\mathrm{e}}$. Injection of a gas containing carbon (e.g. methane) will increase $f_{C}$ and decrease $T_{e}$ (that will be reduced locally by radiative losses in proportion to the rate of gas injection and the radiating efficiency of the elements in the gas), thus when performed near a high-Z PFC surface, it may reduce the surface erosion via creating a protective coating. Injection of a gas not containing carbon (e.g. $\mathrm{D}_{2}$ ) will locally decrease both $\mathrm{f}_{\mathrm{C}}$ (through dilution) and $\mathrm{T}_{\mathrm{e}}$ (as explained above), thus its effect on the deposition is harder to predict. We should note that carbon impurity dilution may be in itself beneficial for reducing high-Z PFC erosion, since carbon is more efficient for sputtering of high-Z elements than deuterium.

\section{Experimental approach}

Exposures of Mo-coated samples were conducted in the lower divertor of the DIII-D tokamak [10]. For net erosion to be measurable by ion beam analysis (IBA), 15-75 nm thick Mo films deposited on $1 \mathrm{~cm}$ diameter silicon disks were used. IBA was also used to measure carbon deposition on top of Mo. In order to discriminate between the carbon originating from the gas injection and that from the background plasma, isotopically enriched ${ }^{13} \mathrm{CH}_{4}$ methane $\left(99 \%{ }^{13} \mathrm{C}\right)$ was used for the injection. The samples pre-characterized by IBA were installed in graphite casings and inserted in the lower divertor of DIII-D using the Divertor Material Evaluation System (DiMES) manipulator [11]. Plasma-facing surface of the samples was flush with the casing surface within $0.05 \mathrm{~mm}$ or better, and the casing surface, when inserted, 
was flush with the surrounding divertor tile surface within $0.1-0.15 \mathrm{~mm}$. For the first two exposures, the Mo-coated samples were mounted in the center of the DiMES head $\sim 5 \mathrm{~cm}$ in diameter [Fig. 4(a-c)]. For the latest two exposures, a DiMES head featuring an embedded Langmuir probe (LP) downstream of the samples was employed [Fig. 4(d)]. The LP allowed measurements of the local plasma density $\left(\mathrm{n}_{\mathrm{e}}\right)$ and $\mathrm{T}_{\mathrm{e}}$ before and during the gas injection. MoI emission near the samples was monitored by an absolutely calibrated digital CMOS camera and a high resolution Multichord Divertor Spectrometer (MDS) [12].

All experiments were performed in deuterium discharges, in a lower single null (LSN) magnetic configuration. Poloidal cross-section of the last closed flux surface, location of DiMES head and arrangement of the main diagnostics are shown in Fig. 2. In the exposure discharges, the outer strike point (OSP) was kept off the DiMES head during the plasma current $\left(\mathrm{I}_{\mathrm{p}}\right)$ ramp-up and ramp-down. Once stable conditions were achieved at $\sim 1 \mathrm{~s}$ into the discharge, the OSP was moved to $1-2 \mathrm{~cm}$ inboard of the center of the DiMES head and dwelled there for 3-4 s in each exposure discharge. Gas was injected through a capillary opening through a hole in a floor tile at the same major radius with the center of the DiMES head and $\sim 12 \mathrm{~cm}$ upstream of it toroidally [Fig 2(b)]. Main $\mathrm{D}_{2}$ gas inlet used to maintain constant discharge density was located at the top of the vessel [Fig. 2(a)] 150 degrees toroidally away from DiMES. $\mathrm{D}_{2}$ puff rate through this valve during flattop part of the discharge was typically around 20 Torr-1/s. Divertor $n_{e}$ and $T_{e}$ were measured by Divertor Thomson Scattering (DTS) [13] located 30 degrees $(\sim 78 \mathrm{~cm})$ toroidally upstream of DiMES and by a floor LP array [14] located 18.5 degrees $(\sim 48 \mathrm{~cm})$ toroidally downstream of DiMES. Poloidal locations of DTS scattering volumes and LPs are shown on the insert in Fig. 2. The LP closest to DiMES (marked by an arrow) is located $1.5 \mathrm{~mm}$ radially outwards of the center of the DiMES head. In order to obtain radial profiles of $n_{e}$ and $T_{e}$, characterization discharges with OSP radial sweeps were run. During these discharges DiMES was retracted. 
In all discharges the toroidal magnetic field $\left(\mathrm{B}_{\mathrm{T}}\right)$ and the plasma current were in the "normal" direction, meaning $B_{T}$ was clockwise and $I_{p}$ was counter-clockwise when viewed from above. The vertical component of the total magnetic field at DiMES location was directed down, so the plasma flow towards the divertor plates was toroidally co-directed with $\mathrm{B}_{\mathrm{T}}$. The angle of incidence of the field lines on the plate was 1.5-1.6 degrees in the low confinement (L-mode) and 2.1 degrees in the high confinement (H-mode) discharges. All discharges used $\mathrm{B}_{\mathrm{T}}=2.0 \mathrm{~T}, \mathrm{I}_{\mathrm{p}}=1.07 \mathrm{MA}$. The line-average electron density was 2.35$2.4 \times 10^{19} \mathrm{~m}^{-3}$ in L-mode discharges and $4.1-5.7 \times 10^{19} \mathrm{~m}^{-3}$ in H-mode discharges. Neutral Beam Injection (NBI) heating power was 0.6 MW in L-mode and 3.8 MW in H-mode, and total heating power (NBI+Ohmic) was about 1.3 and 4.1 MW, respectively.

\section{Experimental results}

\subsection{Experiments with ${ }^{13} \mathrm{CH}_{4}$ gas injection}

Three sample exposures were performed with ${ }^{13} \mathrm{CH}_{4}$ gas injection. Exposure \#1 was performed in four L-mode discharges (shots \#154588-91), exposure \#2 in two H-mode discharges (shots \#154593, 95), and exposure \#3 in three L-mode discharges (shots \#15683638). In the first two discharges of exposure \#1 gas injection started at $2.5 \mathrm{~s}$ [Fig $z \underline{3}$ (a), dashed line], 1.5 seconds after the OSP was moved to DiMES. In the last two discharges of exposure $\# 1$ and in both discharges of exposure \#2, gas injection started at $1.0 \mathrm{~s}$, concurrently with the OSP move to DiMES. In all three discharges of exposure \#3 gas injection started at $0.25 \mathrm{~s}$, during $\mathrm{I}_{\mathrm{p}}$ ramp-up [Fig $2 \underline{3}$ (a), solid line]. Cumulative exposure times near the OSP (total and with gas injection), divertor plasma parameters measured by DTS and LPs, and cumulative $\mathrm{D}^{+}$ ion fluence incident on the samples are summarized in Table 1. H-mode discharges featured Edge Localized Modes (ELMs) with repetition frequency of 50-70 Hz and duration of 2-4 ms.

Divertor plasma parameters during ELMs were hard to resolve, so inter-ELM plasma parameters are given in Table 1. 
Figure 3(b) shows temporal evolution of the MoI emission at $386.4 \mathrm{~nm}$ measured by the MDS spectrometer with ${ }^{13} \mathrm{CH}_{4}$ gas injection in the first discharge of exposure \#1 and the first discharge of exposure \#3 (calibrations were applied to put both signals on the same scale). In shot \# 154588 with ${ }^{13} \mathrm{CH}_{4}$ injection rate of 0.5 Torr-1/s, the measured emission was reduced by about a factor of 2 after beginning of the injection. In subsequent discharges gas injection rate was increased to 1.5 Torr- $1 / \mathrm{s}$, and the MoI signal was further reduced. In the following $\mathrm{H}$ mode exposure the injection rate was increased to $2.8 \mathrm{Torr}-1 / \mathrm{s}$ in order to guarantee MoI signal suppression. While having no measurable effect on the global discharge parameters (as illustrated for the line-averaged density in Fig. 3(c)), the injection was slightly disturbing to the divertor plasma parameters. Figures $3(\mathrm{~d}, \mathrm{e})$ show $\mathrm{n}_{\mathrm{e}}$ and $\mathrm{T}_{\mathrm{e}}$ measured by the downstream floor LP closest to DiMES in shot \# 154588. Even at the injection rate of 0.5 Torr- $1 / \mathrm{s}$, there is a notable reduction of $\mathrm{T}_{\mathrm{e}}$ (by $\sim 25 \%$ ) and increase of $\mathrm{n}_{\mathrm{e}}$ (by $\sim 15 \%$ ). In subsequent shots with the injection rate of .5 Torr-1/s, similar effect was also observed on DTS-measured upstream $\mathrm{n}_{\mathrm{e}}$ and $\mathrm{T}_{\mathrm{e}}$, though the relative change was smaller than for LP data in Fig. 3.

The aim of exposure \#3 was to repeat exposure \#1 at constant reproducible conditions and with the local $\mathrm{T}_{\mathrm{e}}$ measured by the embedded LP in order to obtain data set suitable to benchmark future modeling of the local erosion/deposition. In order to guarantee Mo erosion suppression throughout the exposure, ${ }^{13} \mathrm{CH}_{4}$ gas injection started early in the discharge at an injection rate of 1.8 Torr-1/s, which was slightly above the 1.5 Torr-1/s rate shown sufficient to suppress Mo erosion in exposure \#1. Measured MoI emission in all three discharges of exposure \#3 was at the noise background level [Fig. 3(b)].

Visible carbon deposits were observed upon removal on all samples exposed with ${ }^{13} \mathrm{CH}_{4}$ gas injection [Fig. 4 (b-d)]. On the samples exposed in L-mode, the deposits formed a welldefined toroidal stripe, while on the sample exposed in H-mode, the deposition pattern was less regular, possibly due to the effect of ELMs causing transient widening of the scrape-off 
layer. OSP position control in H-mode was also not as good as in L-mode, possibly contributing to the spreading of the deposition pattern.

\subsection{Experiment with $D_{2}$ gas injection}

Exposure \#4 was performed with $\mathrm{D}_{2}$ upstream gas injection in three L-mode discharges (shots \#156832-34). During this exposure $\mathrm{D}_{2}$ injection started at $2.5 \mathrm{~s}$ into the discharge, then at $3.5 \mathrm{~s}$ the injection rate was increased [Fig. 5(a)]. The first two discharges featured another injection rate increase at $4.5 \mathrm{~s}$. Temporal evolution of MoI signal at $386.4 \mathrm{~nm}$ measured by MDS spectrometer in the $2^{\text {nd }}$ and $3^{\text {rd }}$ exposure discharges is shown in Fig. 5(b). Injection at rates up to 10 Torr-1/s had no measurable effect on the global discharge parameters (illustrated for the line-averaged density in Fig. 5(c)). MoI signal reduction at injection rates of a few Torr-1/s was barely noticeable, while at 10 Torr-1/s it was reduced by about a factor of 3 . At injection rates of 15-25 Torr-1/s, MoI signal went down to about the noise background level. However, these high injection rates were globally disturbing to the discharge. Also shown in Fig. 5(a) are flow rates of $\mathrm{D}_{2}$ through the main gas inlet used for the discharge density feedback control. $\mathrm{D}_{2}$ injection through the floor inlet at $\sim 15$ Torr-1/s in shot \#156833 was already perturbing enough to replace part of the main gas flow and cause $\sim 2 \%$ increase of the line-average density [Fig.5(c)]. Injection at 25 Torr-1/s in shot \#156834 completely replaced $\mathrm{D}_{2}$ supply through the main valve and resulted in $\sim 5 \%$ increase of the line-average density [Fig.5(c)]. Temporal evolution of $n_{e}$ and $T_{e}$ measured by the LP embedded in the DiMES head in shot 156834 is shown in Figs. 5(d,e). At injection rate of 10 Torr-1/s, $\mathrm{T}_{\mathrm{e}}$ went down from $\sim 35 \mathrm{eV}$ to below $20 \mathrm{eV}$ and $\mathrm{n}_{\mathrm{e}}$ increased by about a factor of 2.5. At higher injection rate $\mathrm{T}_{\mathrm{e}}$ was further reduced to $\sim 10 \mathrm{eV}$ and $\mathrm{n}_{\mathrm{e}}$ increased to almost 3 times the pre-injection level.

\subsection{IBA analysis results}

Net erosion of Mo and deposition of carbon were measured by post-mortem IBA [15]. Mo erosion was measured by Rutherford backscattering spectroscopy (RBS) with $2 \mathrm{MeV}^{4} \mathrm{He}$; 
$\mathrm{C}$ and $\mathrm{D}$ deposition were measured by nuclear reaction analysis (NRA) with $2.5 \mathrm{MeV}{ }^{3} \mathrm{He}$. Results of IBA analysis for all exposures are summarized in Table 1. The numbers shown in the table for the net erosion of Mo are for the centers of the samples. Deposition thickness calculated from the NRA measurements assuming a deposited $\mathrm{C}$ density of $2 \mathrm{~g} / \mathrm{cm}^{3}$ is listed in Table 1 separately for ${ }^{13} \mathrm{C}$ and ${ }^{12} \mathrm{C}$. The average total carbon $\left({ }^{13} \mathrm{C}+{ }^{12} \mathrm{C}\right)$ deposition rate was about equal in both L-mode exposures with ${ }^{13} \mathrm{CH}_{4}$ gas injection: $\sim 48 \mathrm{~nm} / \mathrm{s}$ in exposure \#1 (assuming all $\mathrm{C}$ deposition occurred during ${ }^{13} \mathrm{CH}_{4}$ gas injection), and $\sim 47 \mathrm{~nm} / \mathrm{s}$ in exposure \#3. In $\mathrm{H}$-mode exposure \#2 the deposition rate was much lower, $\sim 9.7 \mathrm{~nm} / \mathrm{s}$. Measured radial and toroidal profiles of ${ }^{13} \mathrm{C}$ and ${ }^{12} \mathrm{C}$ coverage on the sample \#1 are shown in Fig. 5. Carbon coverage was comparable on sample \#3 and about 9 times lower on sample \#2. The ratio of ${ }^{13} \mathrm{C} /{ }^{12} \mathrm{C}$ carbon in the deposits was $\sim 4.3$ on sample \#1, $\sim 5.2$ on sample \#2, and $\sim 8.7$ on sample \#3. Average $\mathrm{D} /\left({ }^{13} \mathrm{C}+{ }^{12} \mathrm{C}\right)$ ratios are listed in Table 1 . The small amounts of $\mathrm{C}$ and $\mathrm{D}$ measured on sample \#4 exposed with $\mathrm{D}_{2}$ gas injection were likely due to implantation rather than deposition [15], since the sample was undergoing net erosion.

\section{Discussion and summary}

Local ${ }^{13} \mathrm{CH}_{4}$ gas injection proved out to be very efficient in suppressing molybdenum erosion in our experiments. The experiments were performed under plasma conditions previously shown to cause net erosion of both Mo [16] and C [17] without gas injection. The measured net erosion rates of Mo in L-mode with comparable divertor plasma parameters were $0.42-0.73 \mathrm{~nm} / \mathrm{s}[16,17]$. In the present experiments, out of the three samples exposed with ${ }^{13} \mathrm{CH}_{4}$ gas injection only sample \#1 showed net Mo erosion in the center larger than the RBS measurement resolution of $0.5 \mathrm{~nm}$. This was not unexpected since sample \#1 was exposed near the OSP for 1.5 seconds before the start of the ${ }^{13} \mathrm{CH}_{4}$ gas injection in the first two exposure discharges, and in exposures \#2 and \#3 gas injection was on all the time that OSP dwelled near the samples. If we assume that during the first $1.5 \mathrm{~s}$ of the first discharge of 
exposure \#1 net erosion of Mo was occurring at the lowest previously measured rate of 0.42 $\mathrm{nm} / \mathrm{s}$ and in the second exposure discharge no erosion was occurring due to deposits formed in the first discharge, we can account for the $0.63 \mathrm{~nm}$ of the measured $1.0 \mathrm{~nm}$ net erosion. Therefore, for sample \#1 the net erosion rate after the start of ${ }^{13} \mathrm{CH}_{4}$ gas injection would be less than $0.04 \mathrm{~nm} / \mathrm{s}$, showing a reduction by factor of more than 10 compared with previously reported L-mode erosion rates $[16,17]$. Same conclusion applies to sample \#3. We should stress that these results were achieved at low injection rates that did not perturb the global discharge parameters and had only slight effect on the divertor plasma.

The NRA-measured ${ }^{13} \mathrm{C} /{ }^{12} \mathrm{C}$ ratio in deposits on all samples exposed with ${ }^{13} \mathrm{CH}_{4}$ gas injection was 4 or higher, indicating that the deposition was largely from the gas injection. Samples \#1 and \#3 exposed in L-mode had 5 times higher $\mathrm{C}$ deposition rates compared to sample \#2 exposed in $\mathrm{H}$-mode. However, even in $\mathrm{H}$-mode $\mathrm{C}$ deposition rate was $\sim 3$ times higher than the highest $\mathrm{C}$ deposition rate previously reported in DIII-D [18]. The high $\mathrm{D} / \mathrm{C}$ ratios observed on samples \#1 and \#3 are characteristic for "soft" deposits formed at low surface temperature, while the lower D/C ratio of the deposits on sample \#2 indicates "hard" deposits formed at higher temperature.

Since the balance between carbon erosion and deposition depends rather strongly on the surface temperature [Fig. 1], and previous DiMES experiments with actively heated samples demonstrated a strong reduction of the $\mathrm{C}$ deposition rate at elevated surface temperature [18], temperature effects certainly deserve consideration. Direct measurements of the sample surface temperatures were not available in these experiments, but an IR camera at a different toroidal location from DiMES provided measurements of the heat flux incident on the divertor tiles. The incident energy density per L-mode discharge at DiMES major radius was about 60 $\mathrm{J} / \mathrm{cm}^{2}$. Assuming full absorption of the incident energy by the Mo sample surface, no radiation and thermal conduction losses, and sub-second time scale for thermalization of the sample 
surface and bulk temperatures, one can make and upper-bound estimate of the sample temperature rise in one discharge. For the $1 \mathrm{~cm}$ diameter Mo samples with a mass of $\sim 2 \mathrm{~g}$, one gets an increase of about $100^{\circ} \mathrm{C}$. Between the discharges the sample thermalizes with the DiMES casing and the adjacent divertor tiles, so the cumulative temperature rise in a 3-4 discharge exposure should not be much larger. At $130-150^{\circ} \mathrm{C}$ chemical erosion is already increased compared to room temperature, but apparently in our L-mode exposures this increase was not sufficiently strong to prevent very fast $\mathrm{C}$ deposition on the samples. In the first H-mode discharge of exposure \#3 IR camera saturated, and in the second one it malfunctioned. A rough estimate using extrapolation of the saturated data gives incident energy density in excess of $300 \mathrm{~J} / \mathrm{cm}^{2}$ per discharge. Therefore, the surface temperature of the sample could go up by a few hundred degrees. This is probably the main explanation of the 5 times lower $\mathrm{C}$ deposition rate and lower $\mathrm{D} / \mathrm{C}$ ratio compared to L-mode discharges. However, even at the elevated temperatures and higher $\mathrm{T}_{\mathrm{e}}$ in $\mathrm{H}$-mode, ${ }^{13} \mathrm{CH}_{4}$ gas injection at a moderate rate was still able to cause net $\mathrm{C}$ deposition. This is a promising result for possible applications in the future devices with hot walls, where T retention in co-deposits will not be such a pressing issue.

$\mathrm{D}_{2}$ gas injection turned out to be less efficient in suppression of Mo erosion than ${ }^{13} \mathrm{CH}_{4}$, and much higher injection rates globally disturbing to the discharge had to be used to observe MoI light reduction. Net erosion measured on the sample \#4 exposed with $\mathrm{D}_{2}$ injection was substantial at $\sim 9.3 \mathrm{~nm}$. Measurable net erosion of Mo was expected, since the sample was exposed near the OSP for about 1.5 seconds before the start of $\mathrm{D}_{2}$ injection in each of the three exposure discharges. However, even if we assume that during the $4.5 \mathrm{~s}$ exposure without gas injection net erosion of Mo was occurring at the highest previously measured rate of 0.73 $\mathrm{nm} / \mathrm{s}$, it would still be responsible for only $\sim 3.3 \mathrm{~nm}$ of the total net erosion. Therefore, net Mo erosion was probably still occurring during the $\mathrm{D}_{2}$ injection at a significant rate. If we divide 
the total net erosion by the total exposure time including that with $\mathrm{D}_{2}$ injection, we get a rate of $\sim 0.78 \mathrm{~nm} / \mathrm{s}$, which is higher than the highest of the previously measured Mo erosion rates $[16,17]$. This result indicating that net erosion of Mo was not reduced compared to previous experiments without gas puff is in apparent contradiction with the notable reduction of MoI light observed during $\mathrm{D}_{2}$ gas injection [Fig. 5]. A few hypotheses including (i) higher $\mathrm{C}$ impurity content in this experiment compared to previous ones causing higher baseline Mo erosion, (ii) decreased inverse photon efficiency coefficient $(S / X B)$ during $D_{2}$ injection due to decreased $\mathrm{T}_{\mathrm{e}}$ causing reduction of MoI signal, and (iii) collisional de-excitation of Mo atoms by $\mathrm{D}_{2}$ molecules causing reduction of MoI signal, were considered but could not be proved. Hypothesis (i) could not be confirmed because the calibrated MoI $386.4 \mathrm{~nm}$ emission intensity measured by MDS before the start of the gas injection was very close in exposures $\# 1$ and \#4 and also roughly equal to that from earlier experiment with Mo (experiment \#1 in Ref [17]). Hypothesis (ii) is in contradiction with the findings of Ref [19] showing no $T_{e}$ dependence of $\mathrm{S} / \mathrm{XB}$ for the $386.4 \mathrm{~nm}$ MoI line in the $\mathrm{T}_{\mathrm{e}}$ range of interest. Hypothesis (iii) could not be verified because of lack of the collisional de-excitation cross-section data. Further experiments with $\mathrm{W}$ samples and/or He gas injection are proposed to shed more light on this discrepancy.

In summary, we have demonstrated that a local injection of a gas containing low- $\mathrm{Z}$ impurity ( $\mathrm{C}$ in our case) in the vicinity of a small area, high-Z PFC surface (molybdenum in our case) in a tokamak divertor can reduce or suppress surface erosion via creating in-situ a protective renewable coating. The methane injection rates in our experiments were low enough to not disturb the global discharge parameters, though divertor plasma parameters were slightly affected. Protecting larger surfaces will require larger gas injection levels, possibly much more perturbative. However, this problem may be alleviated in larger future devices, where gas puff fueling will be less efficient. We should also note that for the PFC 
surfaces constantly exposed to high $\mathrm{T}_{\mathrm{e}}$ plasma this technique will be hard to implement, as follows from Fig. 1. It is proposed mostly for areas where high $\mathrm{T}_{\mathrm{e}}$ loads exist transiently or for a limited time, so the coating can be replenished between the high $\mathrm{T}_{\mathrm{e}}$ load intervals.

We also tested erosion control with a non-depositing deuterium gas injection. The results are not quite conclusive, so future experiments will be required to further quantify the erosion reduction with non-depositing local gas injection. Since most likely future applications for this technique using both depositing and non-depositing gases will be for protection of the critical PFCs outside of the divertor, future experiments in the main chamber are also proposed.

\section{Acknowledgment}

This material is based upon work supported by the U.S. Department of Energy, Office of Science, Office of Fusion Energy Sciences, using the DIII-D National Fusion Facility, a DOE Office of Science user facility, under Awards DE-FG02-07ER54917, DE-FC02-04ER54698, DE-AC02-09CH11466, and DE-AC52-07NA27344. Sandia is a multi-program laboratory operated by Lockheed Martin Company, for the United States Department of Energy's National Nuclear Security Administration under contract DE-AC04-94AL85000. DIII-D data shown in this paper can be obtained in digital format by following the links at https://fusion.gat.com/global.D3D_DMP. 


\section{References}

[1] G. Federici et al., Nucl. Fusion 41 (2001) 1967

[2] A. Loarte et al., Nucl. Fusion 38 (1998) 331

[3] A.S. Kukushkin et al., "Characteristics of divertor detachment for ITER conditions", this conference P1-070, submitted to J. Nucl. Mater.

[4] G. Mank et al., J. Nucl. Mater. 241-243 (1997) 821

[5] A. Kirschner et al., J. Nucl. Mater. 415 (2011) S239

[6] J.W. Davis et al., Nucl. Fusion 53 (2013) 073008

[7] V. Bobkov et al., Nucl. Fusion 53 (2013) 093018

[8] W. Eckstein "Calculated Sputtering, Reflection and Range Values" IPP Report 9/132 (2002)

[9] J.W. Davis, A.A Haasz, J. Nucl. Mater. 241-243 (1997) 37

[10] J.L. Luxon, Nucl. Fusion 42 (2002) 614

[11] C.P.C. Wong et al., J. Nucl. Mater. 196-198 (1992) 871

[12] N.H. Brooks et al., Rev. Sci. Instrum. 63 (1992) 5167

[13] T.N. Carlstrom, et al., Rev. Sci. Instrum. 68 (1997) 1195

[14] J.G. Watkins, et al., Rev. Sci. Instrum. 79 (2008) 10F125

[15] W.R. Wampler et al., J. Nucl. Mater. 438 (2013) S822

[16] P.C. Stangeby et al., J. Nucl. Mater. 438 (2013) S309

[17] D.L. Rudakov et al., Phys. Scr. T159 (2014) 014030

[18] D.L. Rudakov et al., Phys. Scr. T128 (2007) 29

[19] D. Nishijima et al., J. Phys. B: At. Mol. Opt. Phys. 43 (2010) 225701 
Table 1. Summary of the four gas injection experiments

\begin{tabular}{|c|c|c|c|c|c|c|c|c|c|c|c|c|}
\hline \# & Gas & $\begin{array}{l}\text { Total } \\
\text { time } \\
(\mathrm{s})\end{array}$ & $\begin{array}{c}\text { Time } \\
\text { with } \\
\text { gas (s) }\end{array}$ & $\begin{array}{l}\text { Injection } \\
\text { rate } \\
(\text { Torr-1/s) }\end{array}$ & $\begin{array}{l}\text { Conf. } \\
\text { mode }\end{array}$ & $\mathrm{T}_{\mathrm{e}}(\mathrm{eV})$ & $n_{e}\left(\times 10^{19} \mathrm{~m}^{-3}\right)$ & $\begin{array}{c}\mathrm{D}^{+} \text {fluence } \\
\left(\times 10^{22} \mathrm{~m}^{-2}\right) \\
* *\end{array}$ & $\begin{array}{l}\text { Mo net } \\
\text { erosion } \\
(\mathrm{nm})\end{array}$ & $\begin{array}{c}{ }^{13} \mathrm{C} \\
\text { depos. } \\
(\mathrm{nm})\end{array}$ & $\begin{array}{c}{ }^{12} \mathrm{C} \\
\text { depos. } \\
(\mathrm{nm})\end{array}$ & $\begin{array}{l}\mathrm{D} / \mathrm{C} \\
\text { ratio }\end{array}$ \\
\hline 2 & ${ }^{13} \mathrm{CH}_{4}$ & 7 & 7 & 2.8 & $\mathrm{H}$ & $\begin{array}{c}38 *(\mathrm{LP}) \\
40 \pm 10 *(\mathrm{DTS})\end{array}$ & $\begin{array}{c}1.9^{*}(\mathrm{LP}) \\
2.5 \pm 0.5^{*}(\mathrm{DTS})\end{array}$ & $11.0 \pm 1.6^{*}$ & $<0.5$ & 57 & 11 & 0.14 \\
\hline 4 & $\mathrm{D}_{2}$ & 12 & 7.5 & $0.9-25$ & $\mathrm{~L}$ & $\begin{array}{c}30 \pm 5 \text { (LP) } \\
20 \pm 5 \text { (DTS) }\end{array}$ & $\begin{array}{c}1.3 \pm 0.2 \text { (LP) } \\
2.0 \pm 0.3 \text { (DTS) }\end{array}$ & $7.4 \pm 1.4$ & 9.3 & $\sim 0$ & $\sim 8$ & 0.1 \\
\hline
\end{tabular}

* inter-ELM values, ** calculated for unperturbed plasma parameters without gas injection 


\section{Figure captions}

Fig. 1. Threshold electron temperature for transition from net deposition to net erosion of carbon as a function of the ratio of $C$ to $D$ fluxes to the surface, $f_{C}=\Gamma_{C} / \Gamma_{D}$, at different surface temperatures.

Fig. 2. Experimental setup showing LCFS, poloidal location of DiMES, floor and main gas inlets, views of CMOS camera and MDS (a); poloidal location of DTS scattering volumes and floor LPs (insert); image of the sample taken during exposure \#1 by the camera with $\mathrm{CD} / \mathrm{CH}$ filter (b).

Fig. 3. Time history of the $1^{\text {st }}$ discharge of exposure \#1 (dashed blue lines) and the $1^{\text {st }}$ discharge of exposure \#3 (solid red lines): ${ }^{13} \mathrm{CH}_{4}$ gas injection rate (a); MoI signal at $386.4 \mathrm{~nm}$ measured by MDS spectrometer (b); line-average electron density (c). $n_{e}(d)$ and $T_{e}(e)$ measured by the downstream floor LP closest to DiMES in shot \# 154588 .

Fig. 4. Pre-exposure photograph of a DiMES head with Mo-coated sample in the middle (a), and post-exposure photographs of the samples \#1 (b), \#2 (c), and \#3 (d), all showing visible carbon deposits.

Fig. 5. Time history of the $2^{\text {nd }}$ (dashed blue lines) and $3^{\text {rd }}$ (solid red lines) discharges of exposure \#4: $\mathrm{D}_{2}$ gas injection rates through the floor and main inlets (a); MoI signal at 386.4 $\mathrm{nm}$ measured by MDS spectrometer (b); line-average electron density (c); $\mathrm{n}_{\mathrm{e}}(\mathrm{d})$ and $\mathrm{T}_{\mathrm{e}}(\mathrm{e})$ measured by the LP embedded in DiMES head in shot \# 156834.

Fig. 5. NRA-measured post-exposure radial and toroidal profiles of ${ }^{13} \mathrm{C}$ and ${ }^{12} \mathrm{C}$ coverage on sample \#1. 


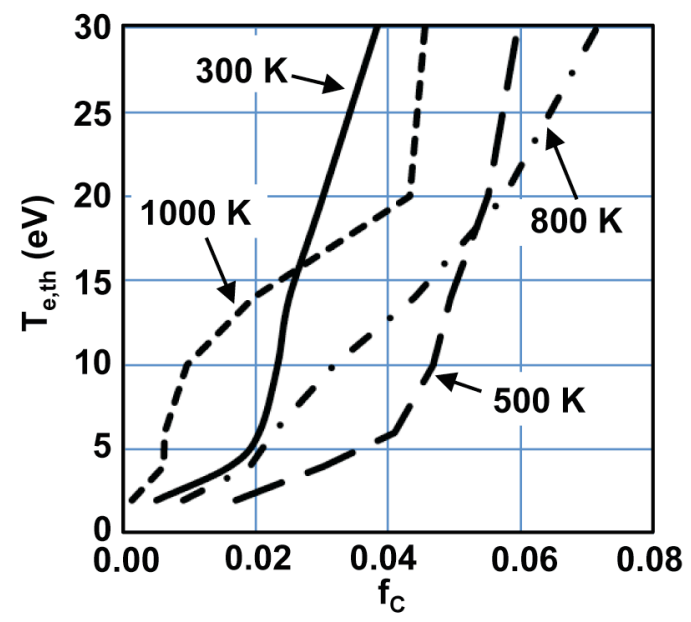

Fig. 1 
(a) Main $D_{2}$ inlet
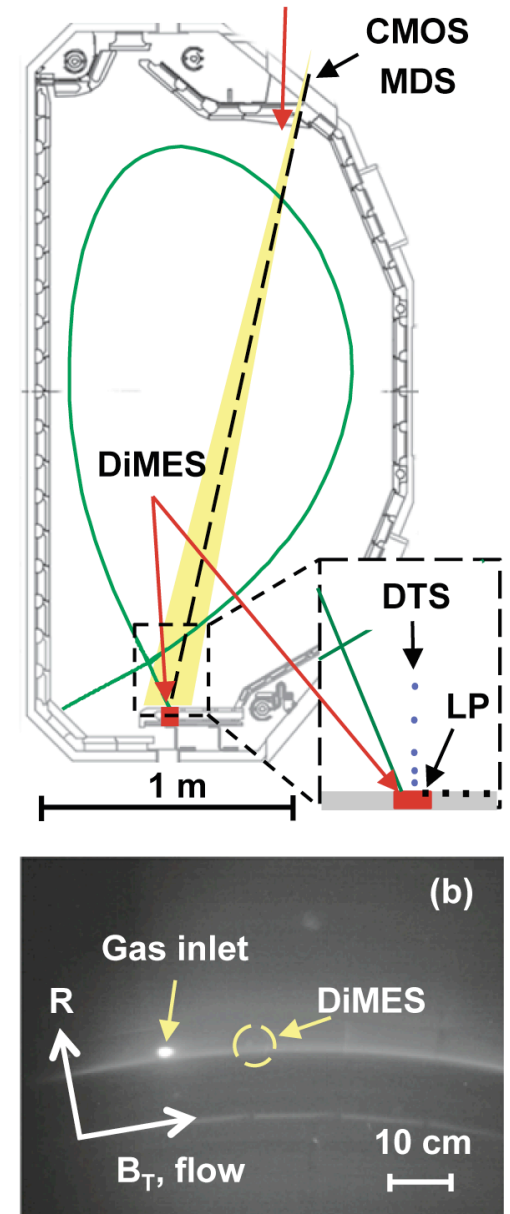

Fig. 2 


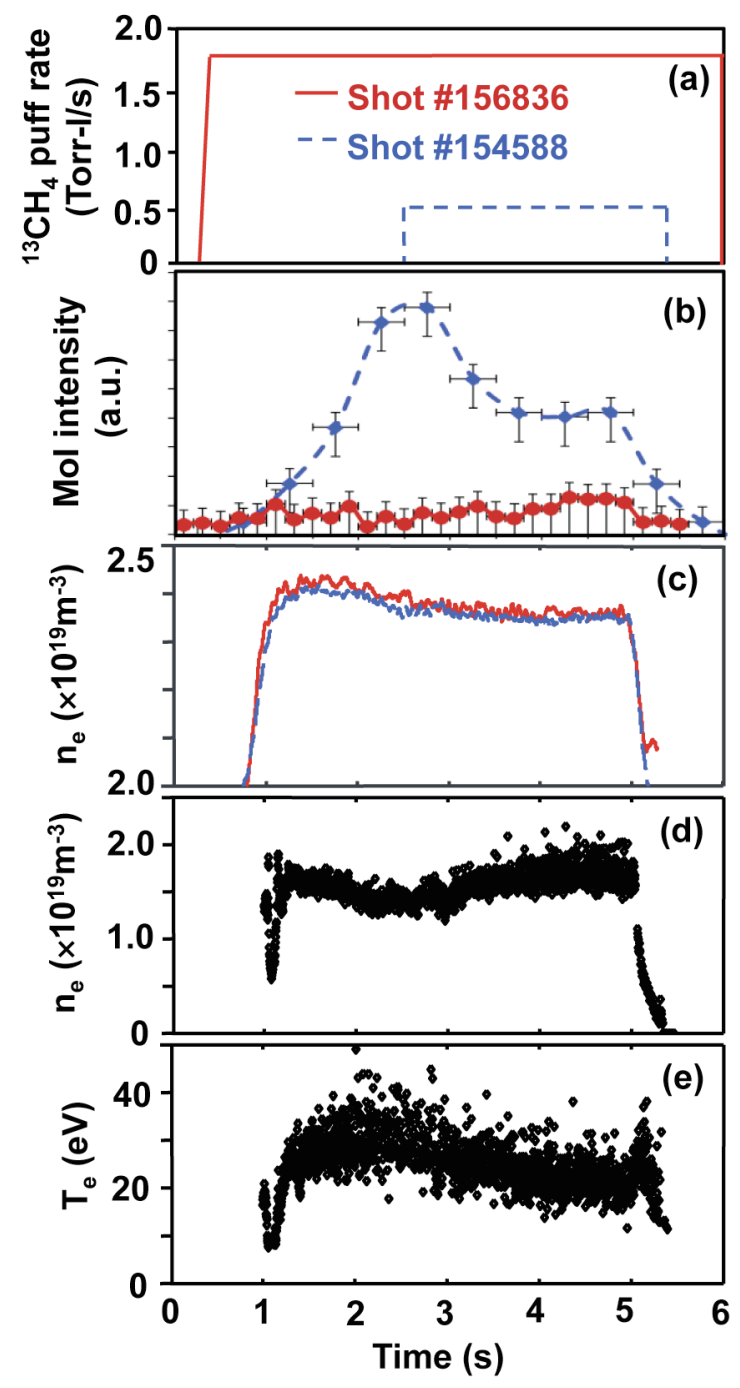

Fig. 3 

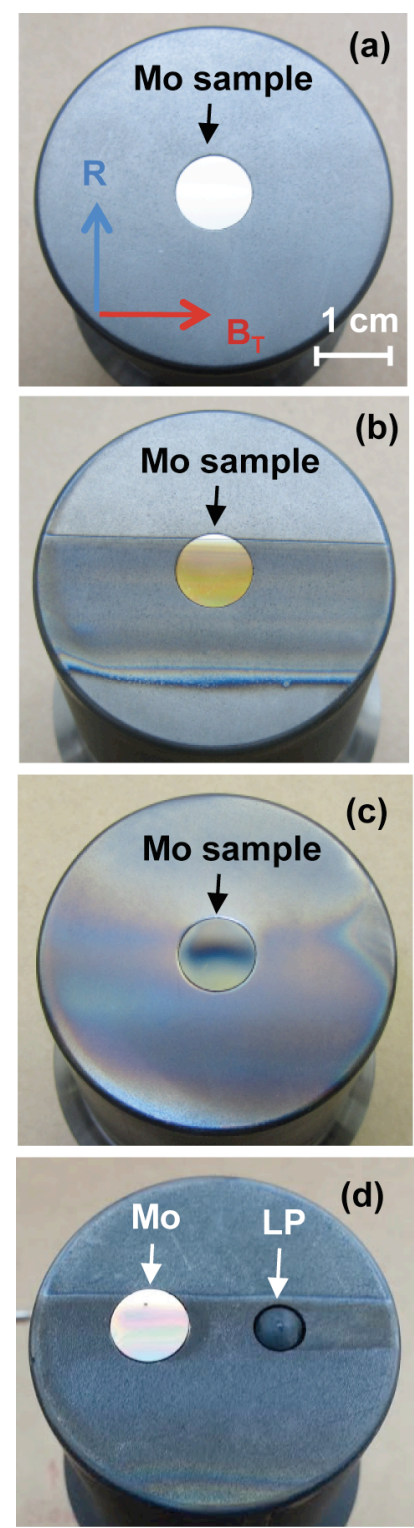

Fig. 4 


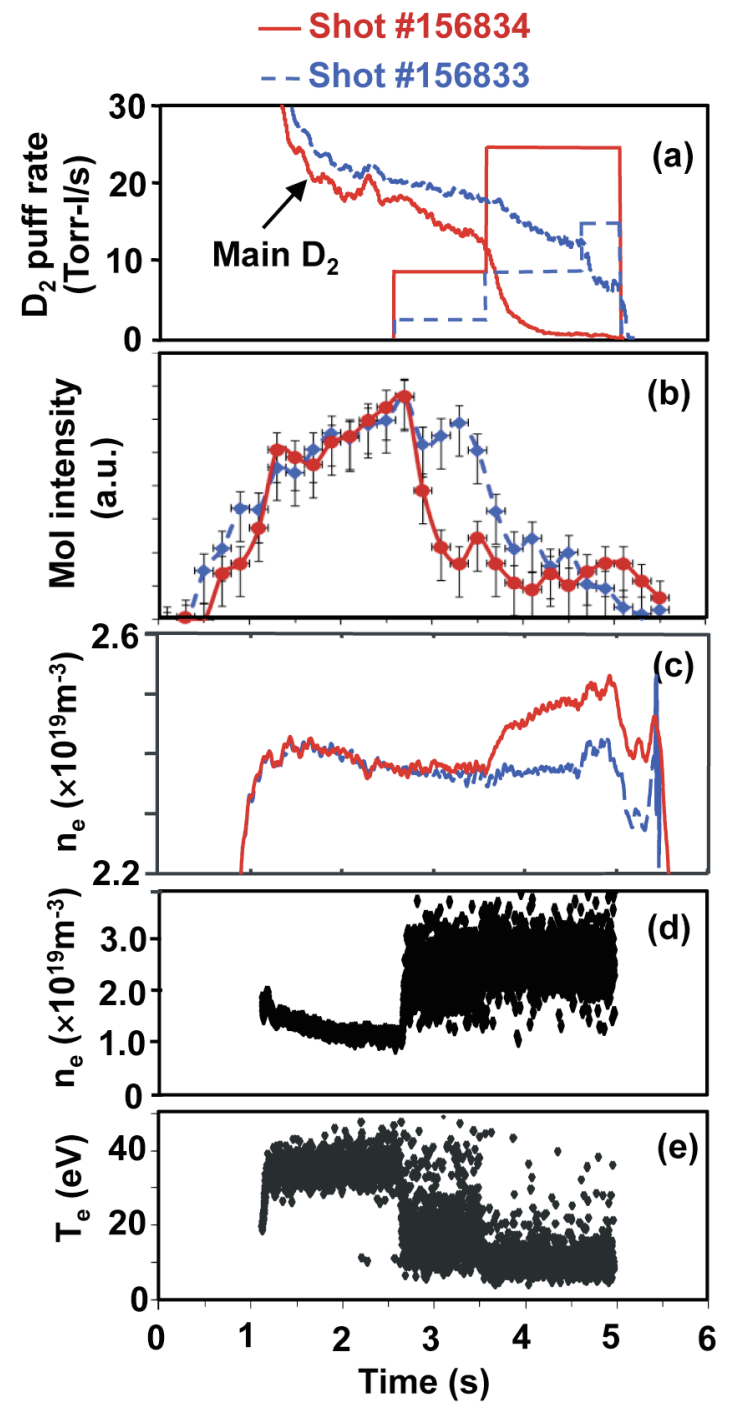

Fig. 5 


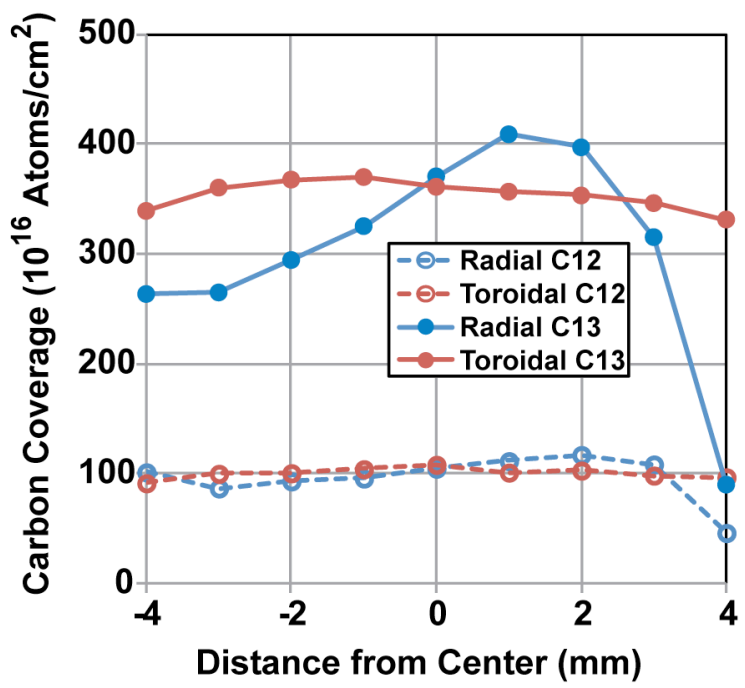

Fig. 6 